\title{
Use and Outcomes of Noninvasive Ventilation for Acute Respiratory Failure in Different Age Groups
}

\author{
Aylin Ozsancak Ugurlu MD, Samy S Sidhom MD MPH, Ali Khodabandeh MD, \\ Michael Ieong MD, Chester Mohr MD, Denis Y Lin MD, Irwin Buchwald MD, \\ Imad Bahhady MD, John Wengryn MD, Vinay Maheshwari MD, and Nicholas S Hill MD
}

\begin{abstract}
BACKGROUND: The prevalence of chronic disease and do-not-intubate status increases with age. Thus, we aimed to determine characteristics and outcomes associated with noninvasive ventilation (NIV) use for acute respiratory failure (ARF) in different age groups. METHODS: A database comprising prospective data collected on site on all adult patients with ARF requiring ventilatory support from 8 acute care hospitals in Massachusetts was used. RESULTS: From a total of 1,225 ventilator starts, overall NIV utilization, success, and in-hospital mortality rates were 22,54 , and $18 \%$ in younger $(18-44 \mathrm{y}) ; 34,65$, and $13 \%$ in middle-aged $(45-64 \mathrm{y}) ; 49,68$, and $17 \%$ in elderly $(65-79 \mathrm{y})$; and 47,76 , and $24 \%$ in aged $(\geq 80 \mathrm{y})$ groups, respectively $(P<.001, P=.08$, and $P=.11$, respectively). NIV use for cardiogenic pulmonary edema and subjects with a do-not-intubate order increased significantly with advancing age $(25,57,57$, and $74 \%$ and $7,12,18$, and $31 \%$, respectively, in the 4 age groups $[P<.001$ and $P=.046$, respectively]). For subjects receiving NIV with a do-not-intubate order, success and in-hospital mortality rates were similar in different age groups $(P=.27$ and $P=.98$, respectively). CONCLUSIONS: NIV use and a do-not-intubate status are more frequent in subjects with ARF $\geq 65 \mathrm{y}$ than in those $<65 \mathrm{y}$, especially for subjects with cardiogenic pulmonary edema. However, NIV success and mortality rates were similar between age groups. (ClinicalTrials.gov registration NCT00458926.) Key words: noninvasive ventilation; acute respiratory failure; elderly; aged; middle-aged. [Respir Care 2016;61(1):36-43. () 2016 Daedalus Enterprises]
\end{abstract}

\section{Introduction}

Based on the United States National In-patient Sample database, the number of hospitalizations for acute respira-

\footnotetext{
Dr Ozsancak Ugurlu is affiliated with the Department of Pulmonary Disease, Baskent University, Istanbul, Turkey. Dr Sidhom is affiliated with the Pulmonary Department, Newton-Wellesley Hospital, Newton, Massachusetts. Dr Khodabandeh is affiliated with Mass Lung and Allergy PC, Leominster, Massachusetts. Dr. Ieong is affiliated with Boston Medical Center, Boston, Massachusetts. Dr Mohr is affiliated with Cape Cod Health Systems, Hyannis, Massachusetts. Dr Lin is affiliated with Lowell General Hospital, Lowell, Massachusetts. Dr Buchwald is affiliated with Saints Medical Center, Lowell, Massachusetts. Dr Bahhady is affiliated with Steward Morton Hospital, Taunton, Massachusetts. Dr Wengryn is affiliated with Jordan Hospital, Plymouth, Massachusetts. Dr Maheshwari is affiliated with Pulmonary Associates, Newark, Delaware. Dr Hill is affiliated with the Department of Pulmonary, Critical Care, and Sleep Medicine, Tufts Medical Center, Boston, Massachusetts.
}

This study was supported in part by an Eli Lilly Distinguished Scholar Award from the Chest Foundation of the American College of Chest tory failure (ARF), one of the most frequent reasons for hospitalization, ${ }^{1}$ almost doubled between 2001 and $2009 .^{2}$ The overall rate of mechanical ventilation remained steady at approximately $50 \%$, but noninvasive ventilation (NIV) increased from 3.8 to $10.1 \%$, whereas the use of invasive mechanical ventilation fell from 48.5 to $42.1 \%$. Older patients $(>85 \mathrm{y})$ more often received NIV than younger ones $(12.7 \%$ vs $7 \%),{ }^{2}$ and were also more apt to have do-notintubate orders than younger ones. ${ }^{3}$ Considering that NIV is frequently offered for management of ARF in patients

\footnotetext{
Physicians. Dr Hill received research grants from Respironics and Breathe Technologies. Dr Ozsancak Ugurlu received a research grant from the Scientific and Technological Research Council of Turkey (TUBITAK). The other authors have disclosed no conflicts of interest.

Correspondence: Aylin Ozsancak Ugurlu, Oymaci sok. No: 2, 34662 Altunizade/Istanbul Turkey. E-mail: aozsancak@hotmail.com.
}

DOI: $10.4187 /$ respcare. 03966 
with do-not-intubate orders as a ceiling of ventilator care or palliative therapy, ${ }^{4-9}$ this also would be expected to favor greater use of NIV in the elderly.

Most prior studies on NIV use in the elderly have been retrospective or based on questionnaires or databases collected on the basis of billing codes,,$^{2,3,10-13}$ limiting the ability to identify clinical characteristics associated with NIV use. Additionally, current data regarding NIV use in the elderly has been derived mainly from hypercapnic subjects treated in ICUs or intermediate care units, ${ }^{4,6,7}$ whereas elderly and do-not-intubate patients are not uncommonly treated on regular medical wards. ${ }^{5}$

In the present study, we used a database collected on site at a group of acute care hospitals in Massachusetts including all patients receiving ventilatory assistance for ARF (hypercapnic/hypoxic) in any hospital location and recorded multiple clinical and physiologic variables. Using this unique database, we sought to determine the utilization rate of NIV as a percentage of all ventilator starts for ARF in each age group and to confirm the hypothesis that NIV is used more often in older age groups. We also assessed subject characteristics and outcomes associated with NIV use in different age groups.

\section{Methods}

\section{Setting and Population}

Our database was designed to study the impact of an educational intervention on NIV utilization and its outcomes for subjects with ARF in 8 hospitals previously found to be low NIV utilizers at the time of a prior NIV survey taken in Massachusetts and Rhode Island. ${ }^{12}$ Of the hospitals, 3 were randomly designated as control, whereas 5 of them were educational intervention sites. The results of the intervention study will be reported separately. The institutional review boards of participating institutions approved the study (Tufts ID 7642) and waived the need for patient consent because it was observational only.

The study was conducted at each institution during sequential 3-month data collection periods at baseline (before) between January 1, 2004, and August 3, 2007, and after the intervention or control periods (after) between August 25, 2005, and December 26, 2009. All subjects receiving mechanical ventilation (either NIV [continuous positive airway pressure or pressure-support ventilation and PEEP] or invasive mechanical ventilation) for ARF were prospectively enrolled hospital-wide, unless they met exclusion criteria (Fig. 1). Subjects were allocated to one of 4 groups based on age: (1) younger $(18-44 \mathrm{y})$, (2) middle-aged (45-64 y), (3) elderly (65-79 y), and (4) aged ( $\geq 80 \mathrm{y}$ ).

\section{QUICK LOOK}

\section{Current knowledge}

Noninvasive ventilation (NIV) represents a standard of care in the treatment of exacerbations of COPD and cardiogenic pulmonary edema. The use of NIV in other causes of acute respiratory failure has met with less success and can delay definitive treatment. NIV has also been used successfully in patients with a do-notintubate status as part of palliative care.

\section{What this paper contributes to our knowledge}

In a review of an existing database, NIV was used more frequently in subjects older than $65 \mathrm{y}$ compared with those $<65$, approaching $50 \%$ of ventilator starts for acute respiratory failure. The use of NIV in these subjects reflects the greater prevalence of chronic lung disease and cardiogenic pulmonary edema in this group. The outcome of do-not-intubate subjects was associated with a higher mortality in both age groups.

\section{Data Collection}

On-site respiratory therapists filled out standardized data forms at the time of mechanical ventilation initiation, including subject demographics and characteristics, etiology of ARF, time and location of initiation, and equipment and settings used. Investigators recorded any missing information post hoc by reviewing medical records on site and recorded duration of use, diagnoses, complications, and clinical outcomes.

The etiology of ARF was allocated to one of 6 subgroups, as described previously ${ }^{14}$ : (1) acute-on-chronic lung disease (ie, COPD and other chronic lung diseases); (2) de novo ARF (ie, pneumonia and ARDS); (3) cardiogenic pulmonary edema; (4) ARF associated with neurologic diseases (including drug or alcohol overdose); (5) cardiopulmonary arrest; and (6) others (postextubation failure, immunosuppressed with ARF, sepsis, shock, and other diseases).

\section{Outcome Variables}

The primary outcome was the utilization rate of NIV as a percentage of all ventilator starts for ARF in each age group. The secondary outcomes were NIV success (defined as avoidance of intubation or death during use of NIV or the subsequent $48 \mathrm{~h})^{14}$ and in-hospital mortality rates per age group. Other secondary outcomes included subject characteristics and physiologic variables, location of use, duration of mechanical ventilation use, and length of stay 


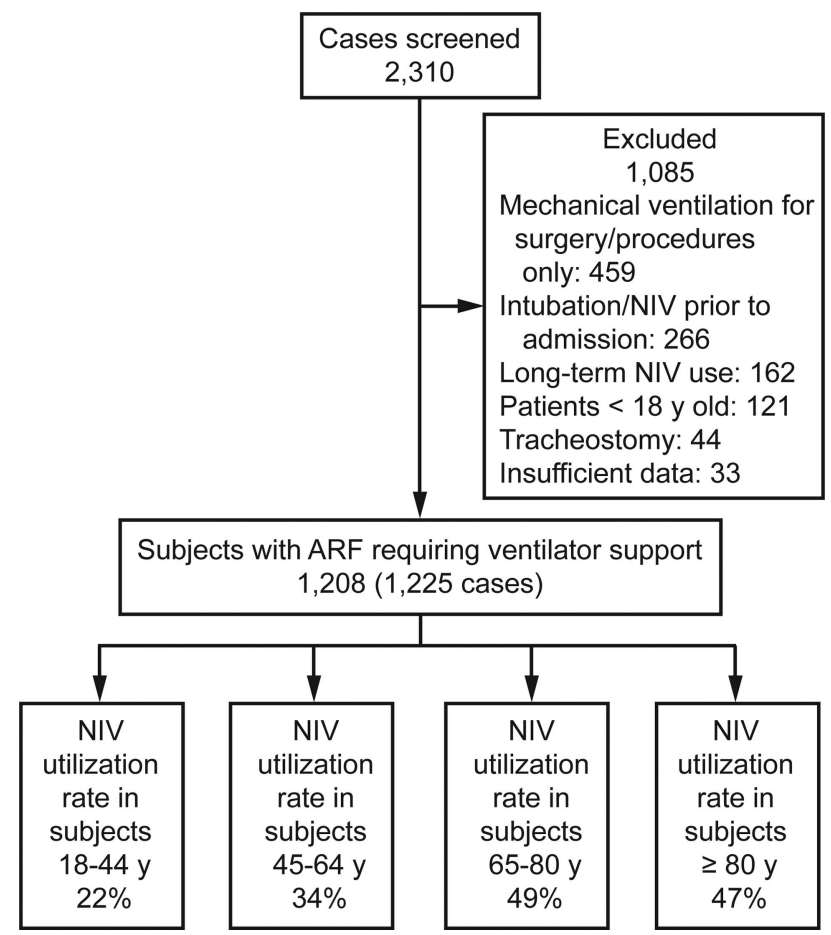

Fig. 1. Flow chart. IMV = invasive invasive mechanical ventilation; $\mathrm{ETI}=$ intubation; NIV = noninvasive ventilation; $\mathrm{ARF}=$ acute respiratory failure.

in hospital. Outcomes were also assessed for subjects with do-not-intubate orders in the different age groups.

\section{Statistical Analysis}

Statistical analysis was performed using SPSS 12.0 (SPSS, Chicago, Illinois). The educational intervention did not consider age, and given that there were no significant differences within age groups between the before and after surveys, we combined subjects from the before and after groups to maximize our numbers.

Continuous variables were expressed as median with interquartile range and compared using the Mann-Whitney $U$ test or Kruskal-Wallis test. The chi-square test (with the Monte Carlo method) was used for categorical data when appropriate. A 2-tailed $P$ value of $<.05$ was considered statistically significant.

\section{Results}

\section{NIV Utilization Rates Per Age Group}

As shown in Figure 1, 1,225 cases of ARF were enrolled into our study. Utilization rate of NIV as a first-line ventilator modality was $41 \%$ among all ventilator starts and $22,34,49$, and $47 \%$ for younger, middle-aged, elderly, and aged groups, respectively $(P<.001)$.

\section{Subject Characteristics}

Compared with invasive mechanical ventilation subjects, NIV subjects were older and more tachypneic with higher systolic and diastolic blood pressures and higher body mass indexes (Table 1). All NIV age groups had lower Simplified Acute Physiology Score II (SAPS II) and more often had a do-not-intubate status than the corresponding invasive mechanical ventilation age groups, as would be expected.

Among subjects receiving NIV, the older age groups had significantly lower body mass indexes, heart rates, and $\mathrm{pH}$ values and higher $\mathrm{P}_{\mathrm{CO}_{2}}$ values, SAPS II, and rates of do-not-intubate orders than the younger and middle-aged groups (Table 1). However; after adjusting for the age effect on SAPS II, the severity of illness was highest in the younger group $(P=.02)$.

NIV subjects were admitted mainly from home in all age groups, followed by other acute care hospitals in younger and nursing/group homes in the other age groups (Table 2). The location of NIV initiation did not differ within the age groups (Table 2). On the other hand, the greatest portion of subjects with a do-not-intubate status initiated on NIV were elderly in the ICU and aged on regular wards $(0,10,51$, and $39 \%(P=.030)$ and 0,14 , 38 , and $48 \%(P=.22)$, respectively). Additionally, irrespective of age, there was an increased use of NIV outside of the ICU for do-not-intubate subjects compared with subjects without a do-not-intubate order (68\% vs $56 \%$, respectively, $P=.03$ ) (Table 2).

Overall, the most common etiology for ARF was neurologic (mainly drug overdoses) in the younger age group, acute-on-chronic lung disease in the elderly, and cardiogenic pulmonary edema in the aged, together with an equal distribution of these in the middle-aged (Fig. 2) $(P<.001)$. Among subjects receiving NIV, pneumonia and other acute lung diseases predominated in the younger, acute-onchronic lung disease in the middle-aged, and elderly and cardiogenic pulmonary edema in the aged groups (Fig. 3) $(P<.001)$.

\section{NIV Success and Mortality Rates and Other Outcomes}

Overall NIV success and mortality rates were similar between age groups regardless of do-not-intubate status (Table 3, $P=.08$ and .12, respectively). As anticipated, overall in-hospital mortality was significantly lower for NIV than invasive mechanical ventilation subjects $(18 \%$ vs $32 \%$, respectively, $P<.001$ ), but mortality rates were similar between the NIV and invasive mechanical ventilation groups for younger subjects (18\% vs $14 \%$, respectively, $P=.61$ ). Among subjects receiving NIV, aged subjects ( $\geq 80 \mathrm{y}$ ) had significantly higher NIV success and mortality rates than the 


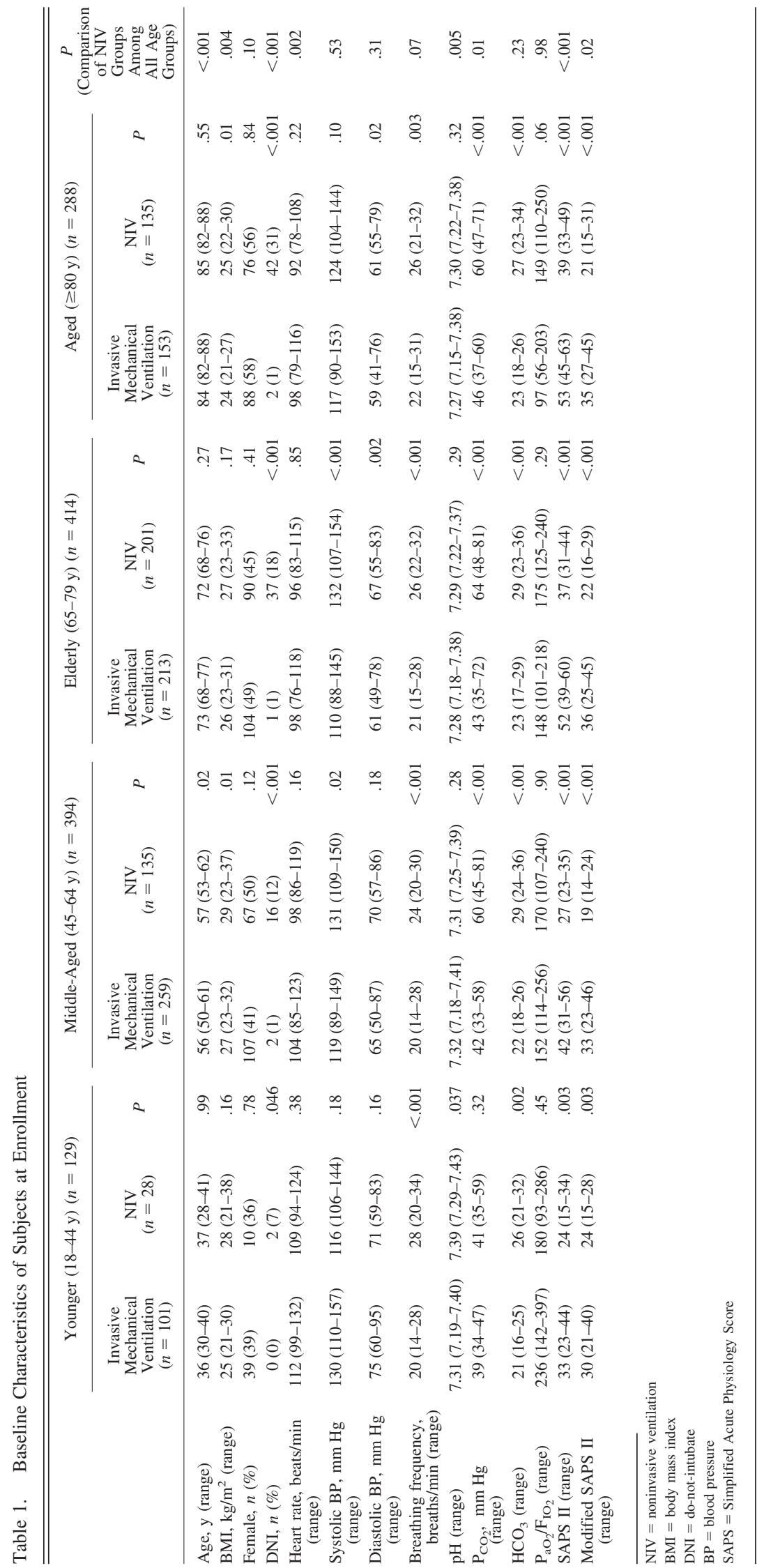


Table 2. Location of Admittance From and Noninvasive Ventilation (NIV) Initiation for All NIV Subjects and NIV Subjects With Do-NotIntubate Order

\begin{tabular}{|c|c|c|c|c|}
\hline & $\begin{array}{c}18-44 \text { y } \\
(\mathrm{All} / \mathrm{DNI} n=28 / 2)\end{array}$ & $\begin{array}{c}45-64 \mathrm{y} \\
(\mathrm{All} / \mathrm{DNI} n=135 / 16)\end{array}$ & $\begin{array}{c}65-79 \text { y } \\
\text { (All/DNI } n=201 / 37)\end{array}$ & $\begin{array}{c}\geq 80 \mathrm{y} \\
(\mathrm{All} / \mathrm{DNI} n=135 / 42)\end{array}$ \\
\hline \multicolumn{5}{|l|}{ Admitted from* } \\
\hline Home & $20(74) / 2(100)$ & $106(78) / 10(63)$ & $167(83) / 27(73)$ & $78(58) / 16(38)$ \\
\hline $\mathrm{NH} /$ group home/AL & $2(7) / 0$ & $22(16) / 6(37)$ & $16(8) / 8(22)$ & $51(38) / 26(62)$ \\
\hline Other acute care hospitals & $5(19) / 0$ & $4(3) / 0$ & $7(4) / 0$ & $3(2) / 0$ \\
\hline Rehabilitation centers & $0 / 0$ & $1(1) / 0$ & $7(4) / 2(5)$ & $2(2) / 0$ \\
\hline Other & $0 / 0$ & $2(2) / 0$ & $1(1) / 0$ & $0 / 0$ \\
\hline \multicolumn{5}{|l|}{ Location of initiation $\uparrow$} \\
\hline ED & $8(29) / 2(100)$ & $54(40) / 9(56)$ & $63(31) / 13(35)$ & $60(44) / 20(48)$ \\
\hline $\mathrm{ICU}$ & $15(53) / 0$ & $49(37) / 3(19)$ & $94(47) / 16(43)$ & $51(38) / 12(28)$ \\
\hline Wards & $5(18) / 0$ & $26(19) / 3(19)$ & $39(19) / 8(22)$ & $21(16) / 10(24)$ \\
\hline Other & $0 / 0$ & $6(4) / 1(6)$ & $5(3) / 0$ & $3(2) / 0$ \\
\hline $\begin{array}{l}\text { Categorical variables are provided as } \\
\text { order, respectively. } \\
* P<.001 ; \text { data were available for } 27 \\
\dagger P=.26 . \\
\mathrm{DNI}=\text { do-not-intubate } \\
\mathrm{NH}=\text { nursing home } \\
\mathrm{AL}=\text { assisted living } \\
\mathrm{ED}=\text { emergency department }\end{array}$ & $\begin{array}{l}\text { subjects and percentage of } \mathrm{s} \\
\text { 8, and } 134 \text { subjects for each }\end{array}$ & $\begin{array}{l}\text { ithin that age group in parenthe } \\
\text {, respectively. }\end{array}$ & Inoninvasive ventilation subject & jects with a do-not-intubate \\
\hline
\end{tabular}

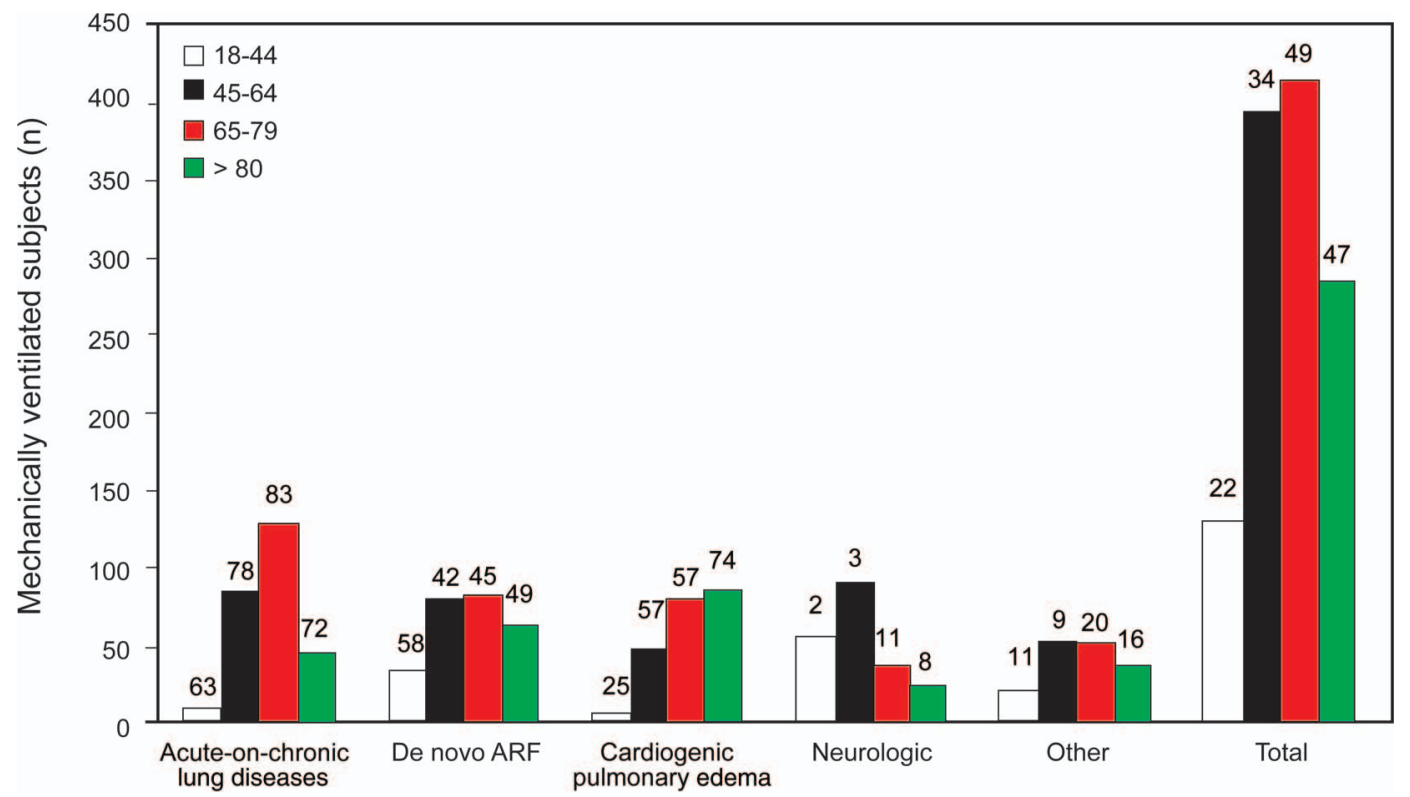

Fig. 2. Number of ventilator starts (including both noninvasive ventilation [NIV] and invasive mechanical ventilation subjects) based on age and etiology of ARF. Numbers above bars are NIV utilization rates (ie, NIV starts/total ventilator starts for acute respiratory failure). $\mathrm{ARF}=$ acute respiratory failure.

combined younger groups ( $<80$ y) $(76 \%$ vs $66 \%$ and $25 \%$ vs $16 \%, P=.040$ and .02 , respectively).

Mean length of stay and total duration of mechanical ventilation were similar between NIV and invasive mechanical ventilation groups for different age groups (data not shown), except for total duration of mechanical ventilation being significantly longer for invasive mechanical ventilation than NIV in aged subjects (4.7 vs $2.6 \mathrm{~d}$, $P=.001)$. Withdrawal of support rates, hospital length of stay for NIV subjects, and duration of NIV use did not differ between age groups (Table 3). Complications (such as pneumonia, gastric distention, pneumothorax, and vomiting into mask) were similarly infrequent in the different age groups. 


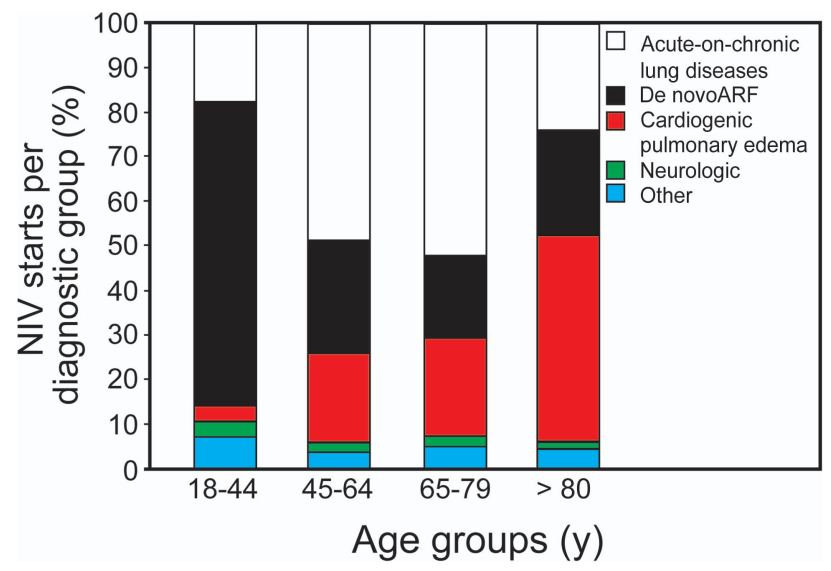

Fig. 3. Distribution of causes of acute respiratory failure (ARF) in subjects using noninvasive ventilation (NIV) according to age groups.

\section{Discussion}

In this prospective cohort study, we found that NIV utilization for ARF as a percentage of all ventilator starts was highest for subjects $>65$ y old and lowest for subjects 18-44 y old, which is probably explained by the greater prevalence of chronic lung or heart disorders in the older and neurologic/toxic conditions (mainly drug and alcohol overdose) in the younger age groups. Additionally, do-notintubate status was observed more frequently with aging, also contributing to greater use of NIV in the elderly and aged. NIV success and in-hospital mortality rates were similar in the different age groups.

A number of previous studies support the use of NIV in older age groups. ${ }^{4-7,15}$ Benhamou et al ${ }^{15}$ reported more frequent use of NIV in elderly subjects with ARF admitted to an ICU (64\%) than in younger subjects (47\%), with higher mortality in the elderly group (21\% vs $9 \%$, respectively) reflecting outcomes in the general ICU population. In a randomized, controlled trial of elderly subjects with hypercapnic ARF admitted to a respiratory care unit, NIV decreased the rate of meeting intubation criteria (7.3 vs $63.4 \%, P<.001$ ) and mortality (odds ratio $=.40, P<.05$ ) compared with standard medical treatment. ${ }^{7}$

Consistent with the above results, our study shows greater utilization of NIV with advancing age. Stefan et $\mathrm{al}^{2}$ also reported increasing use of NIV with age for 1,364,624 medical subjects hospitalized with an ARF diagnosis (12, 21,28 , and $34 \%$ in subjects age 18-44, 45-64, 65-84, and $\geq 85$ y old, respectively). The lower rates of NIV use compared with our study could be due to their reliance on the International Classification of Diseases, Ninth Revision, Clinical Modification (ICD9-CM) coding16; differences in prevalence of etiologies of ARF (pneumonia being the most common diagnosis); or different practices between our hospitals and those in the sample of Stefan et al. ${ }^{2}$ In addition, they observed that older subjects received less invasive mechanical ventilation and less expensive care overall, consistent with earlier studies ${ }^{3,17,18}$ and with the idea that intensity of care decreases with aging as more patients and their proxies choose to limit treatment. In a 2-y prospective cohort study on subjects with ARF admitted to a medical ICU, Schortgen et al ${ }^{6}$ also reported NIV use in $60 \%$ of elderly subjects ( $\geq 80$ y old) requiring ventilator support compared with only $32 \%$ of younger subjects. Our NIV utilization rate in aged subjects was $47 \%$, but this lower rate was in a population with a lower prevalence of do-not-intubate status than in the study by Schortgen et $\mathrm{al}^{6}$ (31\% vs $\left.40 \%\right)$.

With regard to subject characteristics, our older NIV subjects had lower body mass indexes and heart rates with more frequent acidosis, hypercapnia, and do-not-intubate statuses than younger subjects, similar to Schortgen et al. ${ }^{6}$ These differences from younger age groups most likely reflect the greater prevalence of acute-on-chronic lung disease and other chronic illnesses among older patients. Also in our study, the severity of illness increased with age, but after adjustment for age, SAPS II scores were actually higher in the younger age group, due to their greater prevalence of neurologic/toxic and de novo ARF. Reflecting the greater burden of chronic illness, aged subjects were also more likely to be admitted from chronic care facilities compared with other groups.

Contrary to our expectations, age alone did not determine the location of care in our study, but subjects with a do-not-intubate status were more often treated outside of the ICU than those without a do-not-intubate order. In a previous survey, subjects with cancer and their caretakers considered the ICU "a bad place to die."19 Our study found that slightly more than a quarter of elderly do-not-intubate subjects using NIV were treated in the ICU; considerations like need for nursing care and monitoring, bed availability, and patient and/or family preference may override ethical considerations so that a significant minority of such patients still receive ICU care. On the other hand, 10 of 21 (48\%) aged subjects treated on regular wards had a do-not-intubate status as opposed to 11 of $70(16 \%)$ of those $<80$ y $(P=.001)$.

Palliative use of NIV in patients with a do-not-intubate order or when endotracheal intubation is deemed inappropriate has become increasingly common. ${ }^{20,21}$ In our study, a do-not-intubate status imparted a worse prognosis among subjects treated with NIV compared with those without one, undoubtedly related to a higher prevalence of diseases with worse prognoses. However, there was no significant impact of age on outcomes of NIV subjects with a do-notintubate status.

Prior studies have reported conflicting results on the effect of age and the presence of a do-not-intubate order on NIV failure rate. Scarpazza et $\mathrm{al}^{4}$ found that older age 
Table 3. Outcomes of Noninvasive Ventilation (NIV) Based on Age for All NIV Subjects and NIV Subjects With Do-Not-Intubate Orders

\begin{tabular}{|c|c|c|c|c|c|c|}
\hline & $\begin{array}{c}18-44 \text { y } \\
(\mathrm{All} / \mathrm{DNI} n=28 / 2)\end{array}$ & $\begin{array}{c}45-64 \text { y } \\
(\text { All/DNI } n=135 / 16)\end{array}$ & $\begin{array}{c}65-79 \text { y } \\
(\text { All/DNI } n=201 / 37)\end{array}$ & $\begin{array}{c}\geq 80 \mathrm{y} \\
(\text { All/DNI } n=135 / 42)\end{array}$ & $\begin{array}{c}\text { Overall } \\
\text { (All/DNI } n=499 / 97)\end{array}$ & $P$ \\
\hline \multicolumn{7}{|l|}{ Success rates, $\%$} \\
\hline All NIV subjects & 54 & 65 & 68 & 76 & 69 & .08 \\
\hline NIV subjects with DNI & 50 & 56 & 68 & 79 & 70 & .27 \\
\hline NIV subjects without DNI & 54 & 66 & 68 & 74 & 68 & .25 \\
\hline \multicolumn{7}{|l|}{ Mortality rates, $\%$} \\
\hline All NIV subjects & 18 & 13 & 17 & 24 & 18 & .11 \\
\hline NIV subjects with DNI & 50 & 38 & 35 & 33 & 35 & .98 \\
\hline NIV subjects without DNI & 15 & 10 & 13 & 20 & 14 & .17 \\
\hline \multicolumn{7}{|l|}{ Withdrawal of support, $\%$} \\
\hline All NIV subjects & 14 & 10 & 10 & 19 & 13 & .12 \\
\hline NIV subjects with DNI & 50 & 38 & 16 & 26 & 25 & .29 \\
\hline Hospital LOS, d & $11(6-22)$ & $7(4-14)$ & $7(4-13)$ & $7(4-11)$ & $7(4-13)$ & .02 \\
\hline Duration of NIV, $d$ & $0.7(0.1-3.3)$ & $0.7(0.1-2.5)$ & $1.0(0.3-3.2)$ & $0.6(0.2-1.7)$ & $0.8(0.2-1.7)$ & $.02 *$ \\
\hline $\begin{array}{l}\text { Duration of mechanical } \\
\text { ventilation, } d\end{array}$ & $4.8(0.9-9.6)$ & $2.7(0.4-6.3)$ & $2.2(0.5-6.1)$ & $0.9(0.2-6.1)$ & $1.8(0.4-5.5)$ & $<.001$ \\
\hline \multicolumn{7}{|c|}{$\begin{array}{l}* \text { Covers duration of NIV as first iteration. } \\
\text { DNI }=\text { do-not-intubate } \\
\text { NIV }=\text { noninvasive ventilation } \\
\text { LOS = length of stay }\end{array}$} \\
\hline
\end{tabular}

was associated with a higher NIV failure rate. In contrast, in a recent multi-center French database study including 3,163 subjects with ARF requiring ventilator support (but excluding do-not-intubate patients) younger age was found to be one of the independent risk factors for NIV failure $(P<.001) .{ }^{22}$ In the study by Schortgen et al, ${ }^{6}$ NIV failure rates were similar across age groups (40\% vs $42 \%$ in subjects $<80 \mathrm{y}$ and $\geq 80 \mathrm{y}$, respectively), and mortality rates were shown to be higher in the older subjects $(25 \%$ vs $40 \%, P<.01$ ). Our study found no association between the different age groups with regard to success or mortality rates. This may reflect the counterbalancing effects of a higher rate of NIV failure and mortality associated with de novo respiratory failure in the younger age group and the higher rate of withdrawal of support in the aged. On the other hand, when we combined all subjects younger than $80 \mathrm{y}$ and compared them with subjects $>80 \mathrm{y}$, the aged had higher NIV success and mortality rates, probably due to the higher prevalence of chronic disorders and do-notintubate orders, respectively.

Limitations of our study include its observational design and lack of controls, precluding conclusions about the effectiveness of NIV in different age groups. In addition, the data were accrued from selected hospitals in a region of the United States and may not be generalizable to other centers elsewhere. Furthermore, although the number of subjects enrolled is higher than in most of the prior epidemiologic studies, we are limited by small numbers of subjects in some of our subgroups (especially the younger). Our study also has important strengths, including our acquisition of data by prospective identification of sub- jects and on-site data gathering that offers greater reliability compared with off-site survey studies. We have also selected a group of hospitals representing a mix of academic and community settings, providing a real-life snapshot of actual NIV use.

\section{Conclusions}

We conclude that NIV is used more frequently in subjects older than $65 \mathrm{y}$ than in younger subjects, approaching $50 \%$ of ventilator starts for ARF, reflecting the higher prevalence of acute-on-chronic lung disease and cardiogenic pulmonary edema as causes of ARF in the older age groups. NIV is used least often in adults $<45 \mathrm{y}$, reflecting the higher prevalence of neurologic and de novo causes of ARF than in the older age groups, etiologies for which NIV is used infrequently. NIV success and in-hospital mortality rates are similar between age groups. Having a do-not-intubate status is associated with a higher mortality in NIV subjects than in those without one, but age does not affect outcome in do-not-intubate subjects treated with NIV. These data support the routine use of NIV to treat elderly and aged patients with ARF when they have appropriate diagnoses, with the expectation of achieving outcomes at least as good as or even better than those in younger patients.

\section{ACKNOWLEDGMENTS}

We thank the Respiratory Therapy Departments and therapists of the following hospitals: Boston Medical Center (Boston, Massachusetts), Cape Cod Hospital (Hyannis, Massachusetts), Jordan Hospital (Plym- 


\section{NIV for Acute Respiratory Failure in Different Age Groups}

outh, Massachusetts), Lowell General Hospital (Lowell Massachusetts), Steward Morton Hospital (Taunton, Massachusetts), Saints Memorial Medical Center (Lowell, Massachusetts), Tufts Medical Center (Boston, Massachusetts), and Winchester Hospital (Winchester, Massachusetts).

\section{REFERENCES}

1. Cartin-Ceba R, Kojicic M, Li G, Kor DJ, Poulose J, Herasevich V, et al. Epidemiology of critical care syndromes, organ failures, and life-support interventions in a suburban US community. Chest 2011; 140(6): 1447-1455.

2. Stefan MS, Shieh MS, Pekow PS, Rothberg MB, Steingrub JS, Lagu T, Lindenauer PK. Epidemiology and outcomes of acute respiratory failure in the United States, 2001 to 2009: a national survey. J Hosp Med 2013;8(2):76-82.

3. Salottolo K, Offner PJ, Orlando A, Slone DS, Mains CW, Carrick M, Bar-Or D. The epidemiology of do-not-resuscitate orders in patients with trauma: a community level one trauma center observational experience. Scand J Trauma Resusc Emerg Med 2015;23:9.

4. Scarpazza P, Incorvaia C, di Franco G, Raschi S, Usai P, Bernareggi $\mathrm{M}$, et al. Effect of noninvasive mechanical ventilation in elderly patients with hypercapnic acute-on-chronic respiratory failure and a do-not-intubate order. Int J Chron Obstruct Pulmon Dis 2008;3(4): 797-801.

5. Corral-Gudino L, Jorge-Sánchez RJ, García-Aparicio J, HerreroHerrero JI, Lopez-Bernus A, Borao-Cengotita-Bengoa M, et al. Use of noninvasive ventilation on internal wards for elderly patients with limitations to respiratory care: a cohort study. Eur J Clin Invest 2011;41(1):59-69.

6. Schortgen F, Follin A, Piccari L, Roche-Campo F, Carteaux G, Taillandier-Heriche E, et al. Results of noninvasive ventilation in very old patients. Ann Intensive Care 2012;2(1):5.

7. Nava S, Grassi M, Fanfulla F, Domenighetti G, Carlucci A, Perren A, et al. Non-invasive ventilation in elderly patients with acute hypercapnic respiratory failure: a randomised controlled trial. Age Ageing 2011;40(4):444-450.

8. Azoulay E, Kouatchet A, Jaber S, Lambert J, Meziani F, Schmidt M, et al. Noninvasive mechanical ventilation in patients having declined tracheal intubation. Intensive Care Med 2013;39(2):292-301.

9. Nava S, Ferrer M, Esquinas A, Scala R, Groff P, Cosentini R, et al. Palliative use of non-invasive ventilation in end-of-life patients with solid tumours: a randomised feasibility trial. Lancet Oncol 2013; 14(3):219-227.

10. Chandra D, Stamm JA, Taylor B, Ramos RM, Satterwhite L, Krishnan JA, et al. Outcomes of noninvasive ventilation for acute exac- erbations of chronic obstructive pulmonary disease in the United States, 1998-2008. Am J Respir Crit Care Med 2012;185(2):152159.

11. Crimi C, Noto A, Princi P, Esquinas A, Nava S. A European survey of noninvasive ventilation practices. Eur Respir J 2010;36(2):362369.

12. Maheshwari V, Paioli D, Rothaar R, Hill NS. Utilization of noninvasive ventilation in acute care hospitals: a regional survey. Chest 2006;129(5):1226-1233.

13. Hess DR, Pang JM, Camargo CA Jr. A survey of the use of noninvasive ventilation in academic emergency departments in the United States. Respir Care 2009;54(10):1306-1312.

14. Ozsancak Ugurlu A, Sidhom SS, Khodabandeh A, Ieong M, Mohr C, Lin DY, et al. Use and outcomes of noninvasive positive pressure ventilation in acute care hospitals in Massachusetts. Chest 2014; 145(5):964-971.

15. Benhamou D, Muir JF, Melen B. Mechanical ventilation in elderly patients. Monaldi Arch Chest Dis 1998;53(5):547-551.

16. Centers for Disease Control and Prevention. International Classification of Diseases, Ninth Revision, Clinical Modification (ICD-9CM). http://www.cdc.gov/nchs/icd/icd9cm.htm. Accessed Jan 23, 2015.

17. Hamel MB, Phillips RS, Davis RB, Teno J, Connors AF, Desbiens $\mathrm{N}$, et al. Outcomes and cost-effectiveness of ventilator support and aggressive care for patients with acute respiratory failure due to pneumonia or acute respiratory distress syndrome. Am J Med 2000; 109(8):614-620.

18. Needham DM, Bronskill SE, Calinawan JR, Sibbald WJ, Pronovost PJ, Laupacis A. Projected incidence of mechanical ventilation in Ontario to 2026: preparing for the aging baby boomers. Crit Care Med 2005;33(3):574-579.

19. Wright AA, Keating NL, Balboni TA, Matulonis UA, Block SD, Prigerson HG. Place of death: correlations with quality of life of patients with cancer and predictors of bereaved caregivers' mental health. J Clin Oncol 2010;28(29):4457-4464.

20. Azoulay E, Demoule A, Jaber S, Kouatchet A, Meert AP, Papazian L, Brochard L. Palliative noninvasive ventilation in patients with acute respiratory failure. Intensive Care Med 2011;37(8):1250-1257.

21. Quill CM, Quill TE. Palliative use of noninvasive ventilation: navigating murky waters. J Palliat Med 2014;17(6):657-661.

22. Schnell D, Timsit JF, Darmon M, Vesin A, Goldgran-Toledano D, Dumenil AS, et al. Noninvasive mechanical ventilation in acute respiratory failure: trends in use and outcomes. Intensive Care Med 2014;40(4):582-591. 